\title{
Novel Protein Kinase Inhibitors: SMART Drug Design Technology
}

\author{
Tomi K. Sawyer, Regine S. Bohacek, Chester A. Metcalf III, William C. Shakespeare, Yihan Wang, \\ Raji Sundaramoorthi, Terence Keenan, Surinder Narula, Manfred Weigele, and David C. Dalgarno \\ ARIAD Pharmaceuticals, Cambridge, MA, USA
}

BioTechniques 34:S2-S15 (June 2003)

\section{PROTEIN KINASE INHIBITOR DRUG DISCOVERY: A RETROSPECTIVE}

In retrospect, the emergence of protein kinase drug discovery dates to the identification of the first oncogenic protein kinase, Src, about 25 years ago. This work has led to worldwide research efforts to investigate the genomic and proteomic relationships of protein kinases in disease, cellular mechanisms involving protein kinases in signal transduction, structural biology and modes of both activation and inhibition of protein kinases, and drug discovery focused on novel protein kinase inhibitors (1-20). It is now known that protein kinases constitute a superfamily of therapeutic targets that include $>500$ members relative to recent sequencing of the human genome (21-23). Key classes of protein kinases (Table 1) include receptor tyrosine kinases (e.g., epidermal growth factor receptor [EGFR], platelet-derived growth factor receptor [PDGFR], and vascular endothelial growth factor receptor [VEGFR]), nonreceptor tyrosine kinases (e.g., Src and $\mathrm{Abl}$ ), receptor serine/threonine kinases (e.g., transforming growth factor receptor [TGFR]), and nonreceptor serine/threonine and dual specificity kinases (e.g., cyclin-dependent kinase $[\mathrm{CDK}], \mathrm{m}$-Tor, and $\mathrm{MEK}$ ). The tyrosine kinases comprise about 20\% of known or predicted protein kinases.

As highlighted in Figures 1 and 2, key milestones and advances in protein kinase inhibitor drug discovery include focused studies on protein kinase $\mathrm{C}(\mathrm{PKC}), \mathrm{CDK}$, MEK, $\mathrm{p} 38$ mitogen-activated protein kinase (MAPK), Abl kinase, Src kinase, insulin receptor kinase (IRK), and EGFR kinase. Such work has embraced an increased understanding of the roles of protein kinases in signal transduction pathways, including aberrant cellular mechanisms underlying cancer (e.g., PKC, CDK, Abl kinase, Src kinase, and several growth factor receptor kinases). Structural studies have contributed significantly to recent drug discovery campaigns (e.g., nonreceptor kinases, such as Src, Lck, and Abl kinase, and several growth factor receptor kinases). Although the major mode of inhibition of protein kinases has been focused on the ATP binding site, there have been recent achievements made to exploit both allosteric and substrate binding site interactions to advance novel molecules (vide infra). Importantly, very recent Food and Drug Administration (FDA) approvals of both Gleevec ${ }^{\mathrm{TM}}$ (STI-571; Novartis AG International, Basel, Switzerland) (24-26) and Iressa ${ }^{\circledR}$ (ZD1839; AstraZeneca, Wilmington, De, USA) (27-29) exemplify success in drug development of tyrosine kinase inhibitors with particular therapeutic indications for certain cancers.

\section{SRC: A PROTOTYPIC PROTEIN KINASE THERAPEUTIC TARGET}

Src was the first oncogenic protein kinase to be fully characterized by functional genomics, structural biology, and a plethora of cellular biology and biochemical studies designed to delin-

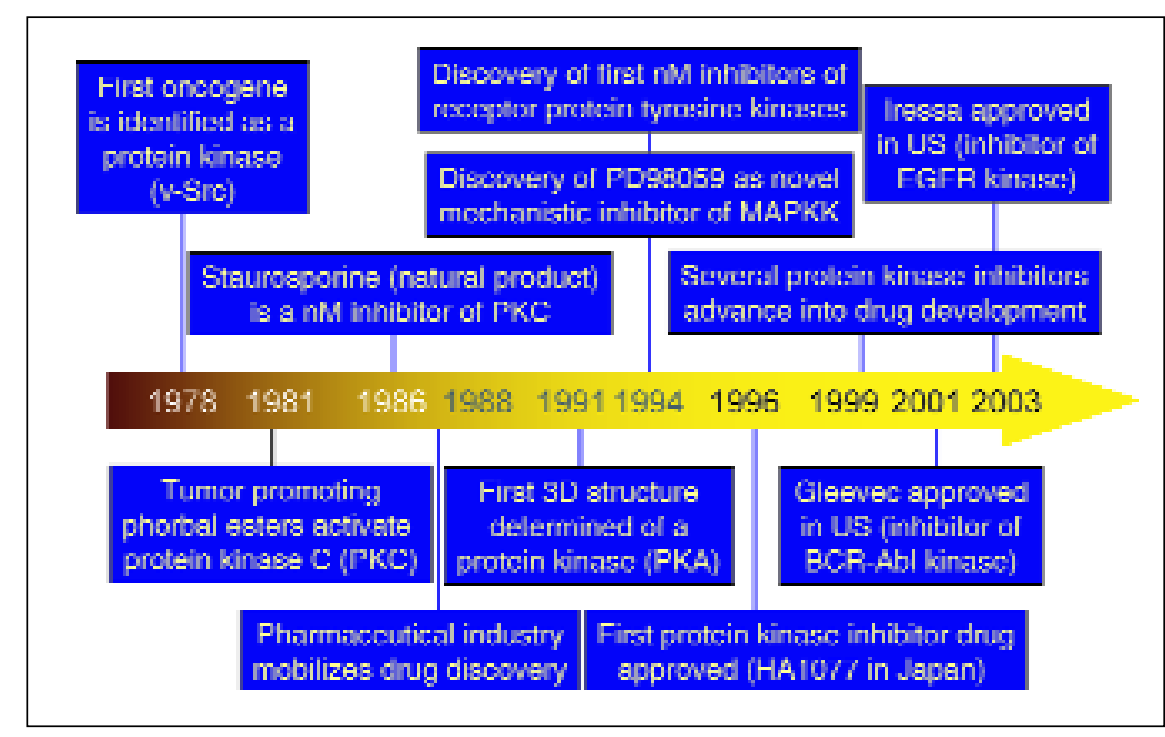

Figure 1. Milestones in protein kinase drug discovery relative to the identification of the first tyrosine kinase oncogene, Src, about 25 years ago. Key achievements and historical events are described [adapted from Cohen (16)], including recent FDA approvals for both Gleevec (STI-571) and Iressa (ZD1839) for the treatment of chronic myeloid leukemia and lung cancer, respectively. 
Table 1. Protein Kinases Relative to Both Receptor and Nonreceptor Classes of Tyrosine and Serine/Threonine (Including Dual Specificity)

\author{
Receptor Tyrosine Kinases \\ Epidermal growth factor receptor \\ Fibroblast growth factor receptor \\ Vascular endothelial growth factor receptor \\ Platelet-derived growth factor receptor \\ Colony-stimulating factor receptor \\ Nerve growth factor receptor \\ Insulin-like growth factor receptor \\ Insulin receptor
}

Nonreceptor Tyrosine Kinases

Src and Src family (e.g., Lck, Hck, Fyn)

$\mathrm{Abl}$ and BCR-Abl

C-terminal Src kinase (CSK)

\section{Receptor Serine/Threonine Kinases}

Transforming growth factor receptor

Nonreceptor Serine/Threonine Kinases

cAMP-dependent protein kinases

Phosphoinositol-3-kinase

Cyclin-dependent kinases (e.g., CDK1, CDK2)

Mitogen-activated protein kinases

Protein kinase-C

Janus-family kinases

IкB-family kinases

mTor (FRAP)

Rho-dependent protein kinase

Akt eate its role in signal transduction pathways and its role in disease processes (1-3,30-33). In the latter regard, Src is unquestionably an intriguing therapeutic target for drug discovery relative to: $(i)$ its requirement in bone remodeling in terms of osteoclast and osteoblast activities and consequential involvement in bone diseases such as osteoporosis and inflammationmediated bone loss; (ii) its functional roles in certain cancers for which transformed phenotypes have been correlated with Src mutations and/or overexpression of Src tyrosine kinase activities; and (iii) its more recently delineated involvement in cancer metastasis as related to signal transduction pathways regulating cell-to-cell interactions. In a historical context, the investigation of Src's signal transduction activities involving both protein phosphorylation and adapter-like properties (via its $\mathrm{SH} 3$ and $\mathrm{SH} 2$ domains; vide infra) to regulate cell growth, cell cycle, ma-

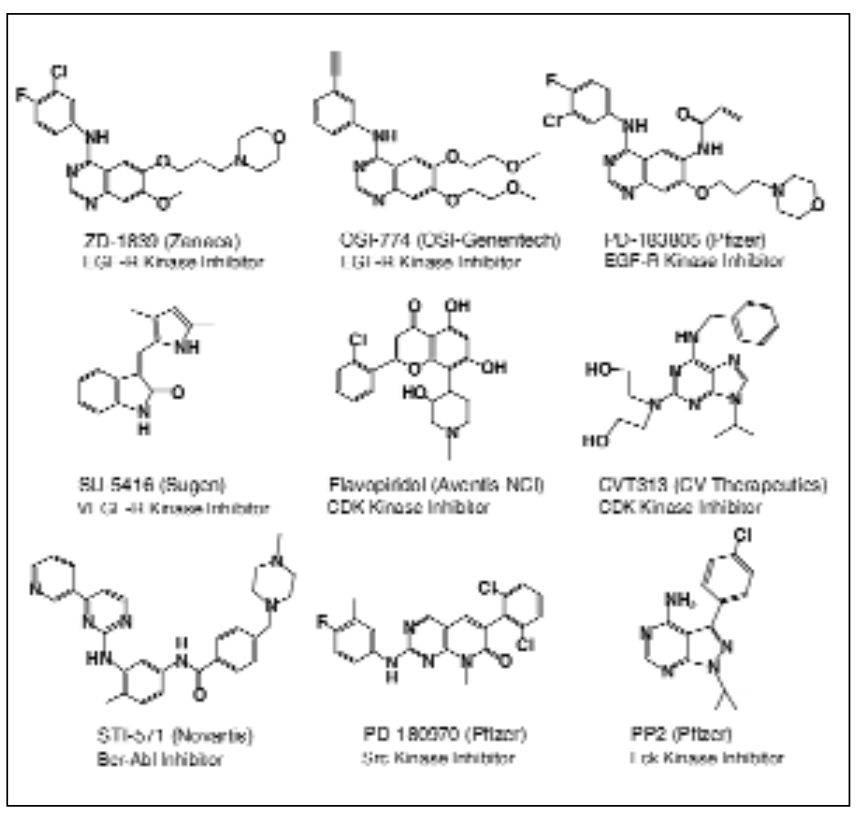

Figure 2. Some examples of protein kinase inhibitors that are in clinical development or have been first shown to exhibit key in vitro (cellular) and/or in vivo activities. lignant transformation, and cell migration (metastasis) has provided significant impetus to drug discovery focused on both itself as well as other protein kinases.

Src gene knock-out mice have revealed the major phenotype of Src deficiency to be osteopetrosis (excessive accumulation of bone in marrow cavities during bone development due to defective bone resorption) and with essentially no other significant in vivo abnormalities (34). Osteoclasts derived from Src-deficient mice are viable, but they are functionally impaired in their ability to resorb bone, because they fail to form ruffled borders (hence, abrogated secretion of acid, proteases, and other bone-metabolizing agents) in vitro and in vivo $(35,36)$. Finally, it is has been shown that osteoblasts from Src gene knock-out mice have increased functional activity $(37,38)$, and such an effect could contribute to an osteopetrotic phenotype. Other targeted gene disruptions of single or multiple members of the Src family kinases (SFKs; vide infra) in mice have been studied (39). Functional genomics studies have also been used to investigate Src activity relative to its negative regulation by C-terminal Src kinase (CSK) (40) as well as positive regulation by protein-tyrosine phosphatase-1B (PTP1B) (41).

As illustrated in Figure 3, a variety of cellular receptors regulate Src-dependent signal transduction pathways that ultimately control cancer growth and metastasis, bone remodeling (i.e., osteoclast-dependent bone resorption), and angiogenesis. Such cellular activities intimately involve both Src-dependent and associated signal transduction pathways that affect cell proliferation and transformation, survival, migration and mobility, and vascular permeability. Elevated Src expression or activity has been correlated with tumor growth in specific cancers having ErbB2 or c-Met receptors $(31,42-45)$, by studies using Src-specific antisense DNA $(46,47)$, and the recent identification of activating Src mutations in advanced human colon cancer (48). Elevated Src expression or activity has been found in breast cancer cell lines and malignant breast tumors $(49,50)$. Src has been also implicated in metastatic colon cancer (51), head and neck cancers (52), and pancreatic cancer (53).

Src has significant structural homology with about 10 proteins (collectively referred to as SFKs), including: Fyn, Yes, Yrk, Blk, Fgr, Hck, Lyn, and Frk subfamily members Frk/Rak and Iyk/Bsk. Src's primary structure (Figure 4) includes: (i) an N-terminal myristoylated "unique sequence" of about 70 amino acids; 
(ii) a noncatalytic regulatory $\mathrm{SH} 3$ domain of about 60 amino acids that recognizes Pro-rich cognate proteins; (iii) a noncatalytic regulatory SH2 domain of about 100 amino acids that recognizes pTyr-containing cognate proteins; (iv) the catalytic tyrosine kinase domain of about 300 amino acids arranged in a bi-lobed fashion to provide binding sites for both ATP and substrate; and $(v)$ a C-terminal regulatory sequence that contains a Tyr residue that can be phosphorylated by CSK. Differences between SFK members exists for these component sequences and domains of the Src primary structure. Beyond Src and SFKs, it is important to point out that the $\mathrm{SH} 3$ and $\mathrm{SH} 2$ domains have been further identified in many other intracellular proteins, including kinases, phosphatases, lipases, nucleotide exchange factors, and transcription factors, and have provided therapeutic targets for drug discovery (54-57).

A more detailed understanding of the molecular basis for Src activation was revealed by X-ray crystal structures of the SH3-SH2-catalytic domain structure of Src in its down-regulated inactive conformation (Figure 5) (58). These structures show that the protein exists in compact form, where the $\mathrm{SH} 2$ domain binds a pTyr ligand sequence contained in the $\mathrm{C}$-terminal regulatory tail, and the $\mathrm{SH} 3$ domain binds a linker sequence of amino acids between the $\mathrm{SH} 2$ and catalytic domains. The $\mathrm{SH} 2$ and $\mathrm{SH} 3$ domains are packed against the back of the $\mathrm{N}$ - and C-terminal lobes of the catalytic domain. Furthermore, the down-regulated form of the protein involves an inhibitory conformation of the dephosphorylated activation loop, which precludes substrate binding in the catalytic site. The structures of both individual protein domains and of combinations of domains of Src family members have been studied extensively by both X-ray crystallography and nuclear magnetic resonance (NMR) spectroscopy. For example, the Xray structure of up-regulated, active Lck kinase complexed with several different inhibitors (47) has been determined (vide infra) and provides further insight to understand the $3 \mathrm{D}$ structural basis for the switch between down- and up-regulated forms of the SFKs.
Table 2. Protein Kinase X-Ray Structures that Illustrate Various ATP, Peptide Substrate, and/or Allosteric Binding Site Inhibitors

\section{Receptor Tyrosine Kinases}

Insulin receptor kinase domain complex (AMP-PNP and peptide substrate) Fibroblast growth factor receptor-I kinase domain complexes (PD173074, SU4984, SU5402)

\section{Nonreceptor Tyrosine Kinases}

$\mathrm{Src}(\mathrm{SH} 3, \mathrm{SH} 2$, kinase) apoprotein and complex (AMP-PNP) Lck kinase domain complexes (AMP-PNP, PP2, staurosporine) Abl kinase domain complex (STI-571 analog)

\section{Nonreceptor Serine/Threonine Kinases}

p38 MAPK domain complex (BIRB796)

CDK-2 kinase domain complex $(\mathrm{H} 717)$

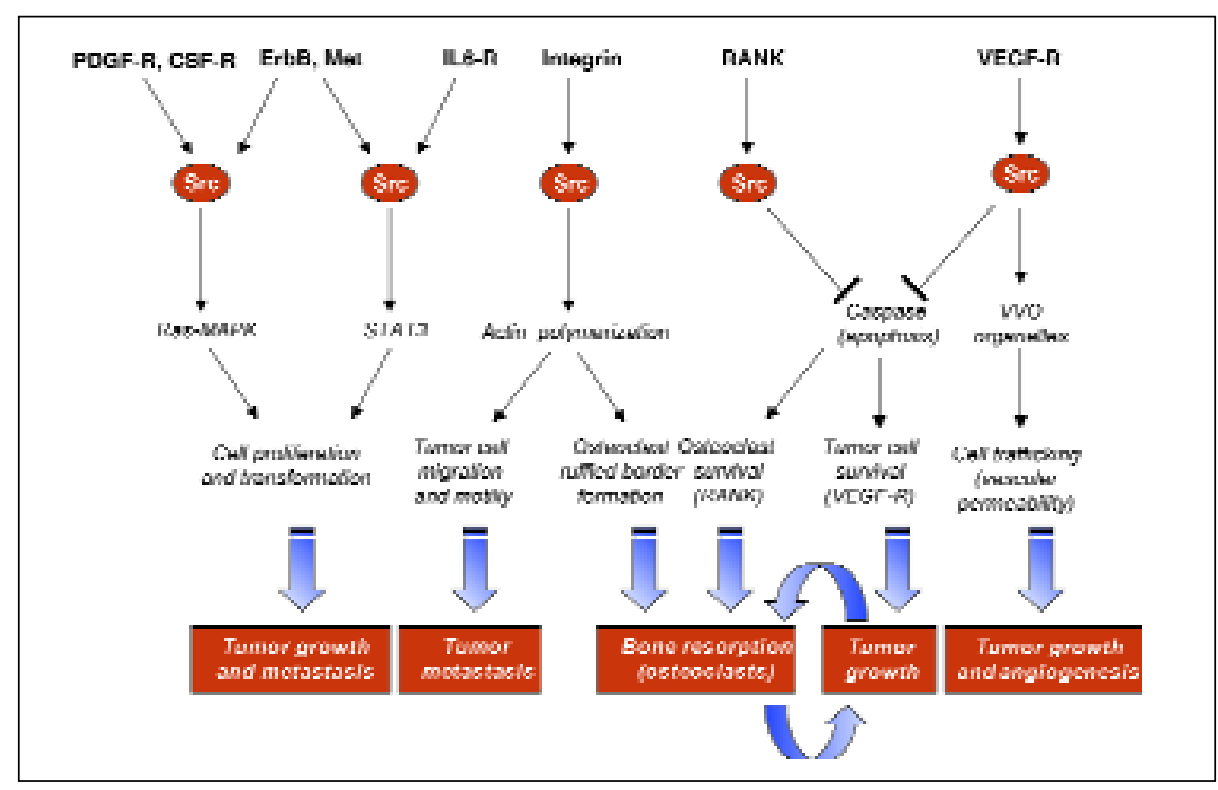

Figure 3. Varying signal transduction pathways known to exist for Src kinase as related to cancer and bone diseases. Such pathways include growth factor receptor-, cytokine-, and integrin-mediated signal transduction via Src kinase to downstream targets and ultimate modulation of cancer cell growth, metastasis, and angiogenesis as well as osteoclast activity [Adapted from Sawyer et al. (1)]. In the case of osteolytic bone metastasis, Src kinase activity may be essential for both osteoclast and cancer cellular activities, which may synergize with each other in a manner often referred to as a "vicious cycle" (highlighted by curved arrows).

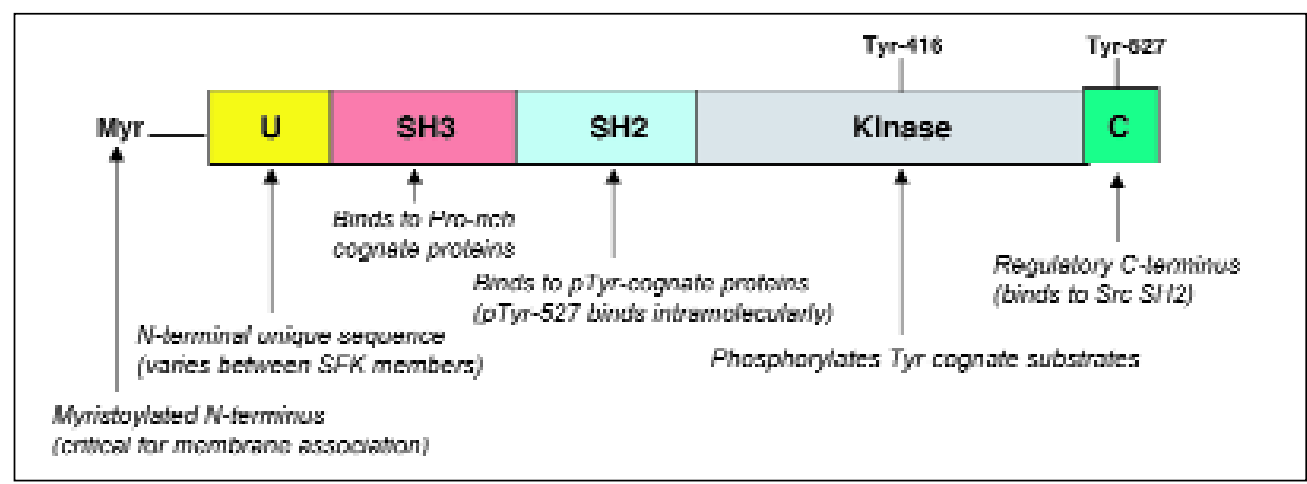

Figure 4. The primary structure of Src kinase showing the N-terminal myristoylated unique sequence, the two noncatalytic domains $\mathrm{SH} 3$ and $\mathrm{SH} 2$, the catalytic kinase domain, and the $\mathrm{C}$-terminal regulatory sequence. Two key tyrosine residues are identified, which provide modulation of the conformational and functional properties of Src (as further detailed in Figure 5). 


\section{STRUCTURAL BIOLOGY OF PROTEIN KINASES AND MODES OF INHIBITION}

Knowledge of the 3D structural properties of protein kinases has grown exponentially over the past few years relative to the first X-ray structure determined for protein kinase A (PKA)

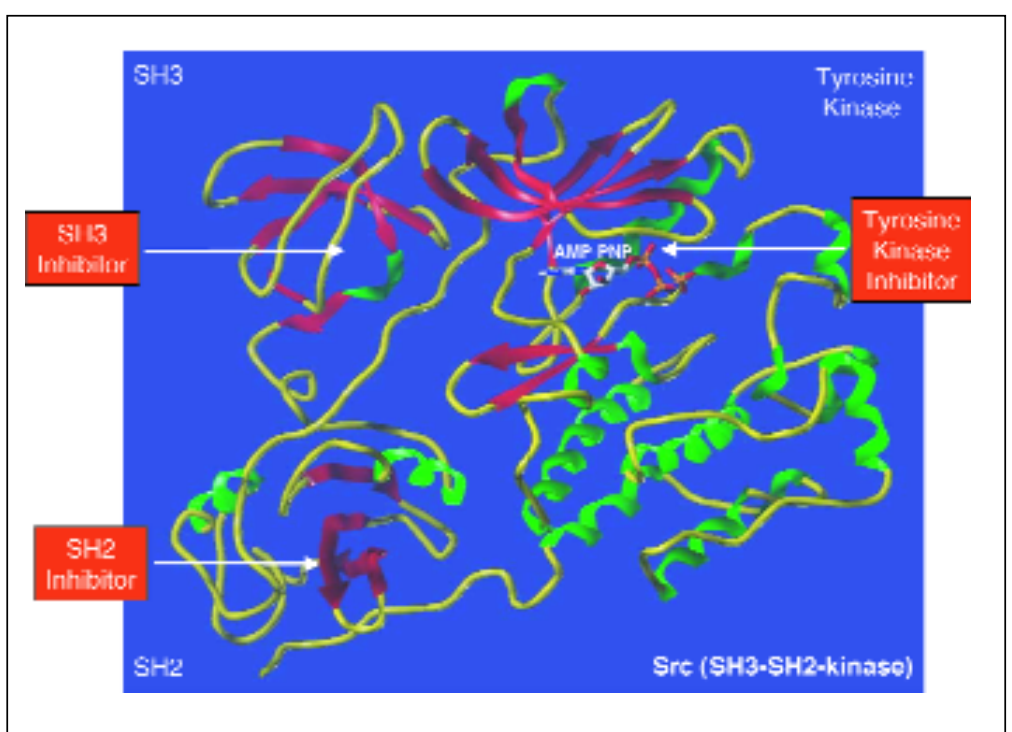

Figure 5. Ribbon representation of a X-ray structure of the Src kinase (SH3-SH2-catalytic construct) in the down-regulated or inactive conformation (58). This Src X-ray structure contains a nonhydrolyzable ATP analog (AMP-PNP). The ribbon is color-coded: $\alpha$-helices, green; $\beta$-sheets, red; loops, yellow. Src inhibitors targeting the $\mathrm{SH} 3, \mathrm{SH} 2$, and kinase domain are highlighted by arrows.

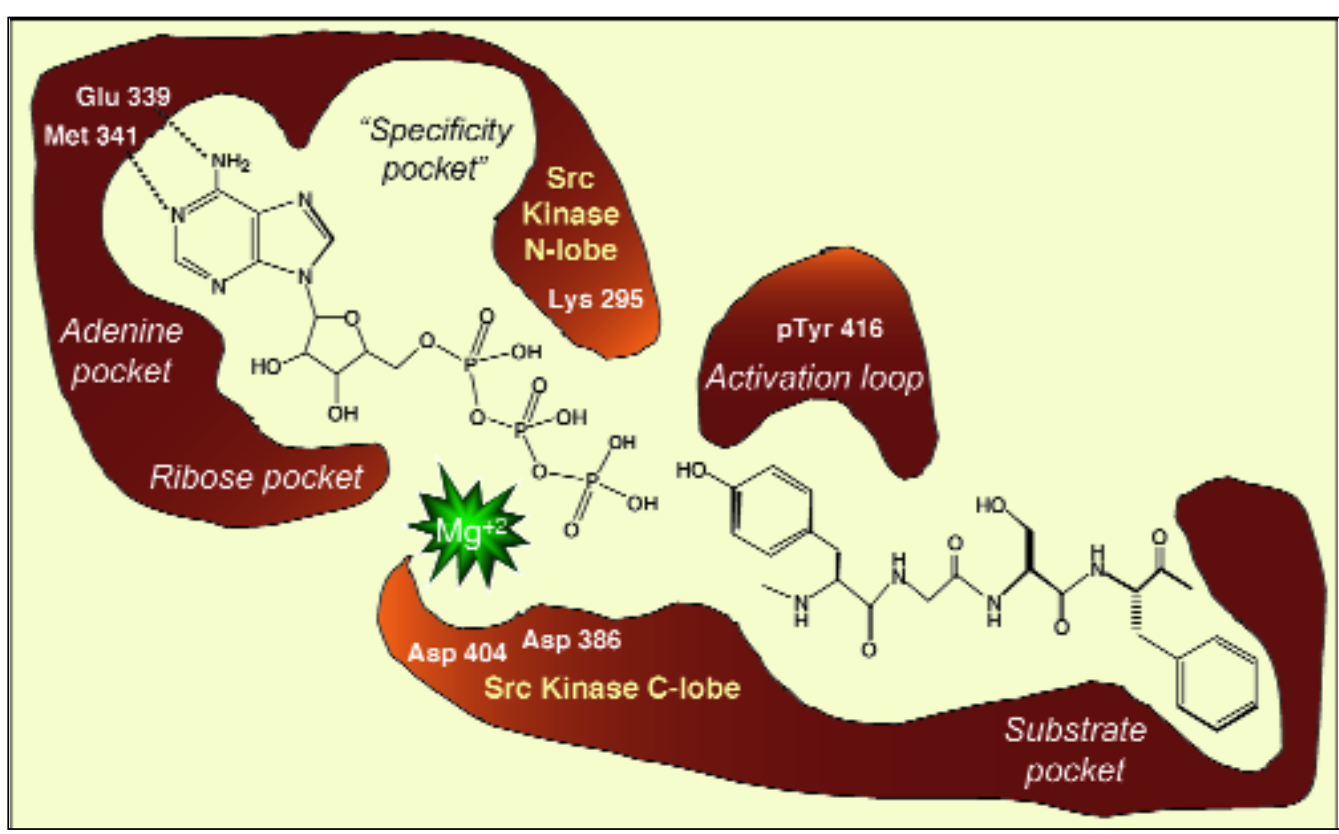

Figure 6. Schematic illustration of ATP and peptide substrate binding to the Src kinase. Note the 3D-defined adenine bind ing pocket and proximate hydrophobic specificity pocket (the latter is not utilized by ATP but is exploited by inhibitors; vide infra). The $\mathrm{N}$ - and C-lobes of Src kinase provide extended binding sites for both ATP and peptide substrate. The divalent metal ion $\mathrm{Mg}^{2+}$ is critical for the transfer of phosphate from ATP to the Tyr residue of the peptide substrate in the active conformation of Src kinase (relative to pTyr-416 of the activation loop). slightly more than 10 years ago. Some examples of X-ray structures of protein kinases complexed with ATP analogs or ATP binding site inhibitors (Table 2) include Src and SFKs (58-60), CSK (61), IRK (62), fibroblast growth factor receptor (FGFR) kinase (63), VEGFR-2 (64), CDK (65-67), and Abl kinase 68). In the case of Src, such 3D structural properties have been also exploited by chemical genomic studies to advance novel ATP analogs modified by hydrophobic groups complementary to mutated Src kinase proteins to investigate the selectivity of substrate phosphorylation in cells (69-71). Simply stated, in the case of Src kinase (and generally accepted for many other protein kinases), the ATP binding pocket includes a hydrophobic specificity pocket that is not utilized by ATP itself, but may be taken advantage of by ATP binding site inhibitors functionalized by complementary hydrophobic groups (Figure 6). In this regard, Src kinase inhibitors of varying templates have been developed that target the hydrophobic specificity pocket of the ATP binding site (vide infra).

The first X-ray structure of a growth factor receptor kinase providing a molecular mapping of both the ATP and substrate binding pockets in complexation with a nonhydrolyzable ATP analog (i.e., AMP-PNP) and peptide substrate analog was that determined for IRK (Figure 7) (62). Furthermore, the IRK ternary complex exemplified the first active conformation 3D structure of a tyrosine kinase and provided insight for molecular modeling of related protein kinases (vide infra). Relative to the SFKs, the first active conformation 3D structure complexed with varying ATP binding site targeted inhibitors (e.g., AMPPNP, the pyrazolopyrimidine analog PP2, and the natural product staurosporine) was that determined for Lck kinase (Figure 8) (59). The first growth factor receptor kinase 3D structure complexed with varying ATP binding site-targeted inhibitors (e.g., PD173074) was that determined for FGFR kinase (Figure 8) (63). The first 3D structure of Abl kinase revealing the unique mode of binding of Gleevec and its inhibition of the inactive form of the enzyme via an allosteric mechanisms (Figure 9) (68) has also provided insight in the design of protein kinase inhibitors having high specificity. Recently, a 3D structure of p38 MAPK complexed with a novel allosteric inhibitor, which binds to the inactive form of the enzyme has been deter- 
mined (72). Other strategies to inhibit protein kinases functionally beyond the ATP and/or substrate binding sites include the noncatalytic SH2 domain of Src (57) and the rapamycin-dependent binding of FKBP12 to mTOR (also referred to as FRAP or FKBP12-rapamycin-associated protein) to effect negative regulation of mTor kinase $(73,74)$.

\section{PROTEIN KINASE INHIBITOR CHEMICAL DIVERSITY}

The design of Src tyrosine inhibitors has focused on a number of strategies (1-20) and has included ATP-related templates (Figure 10) as well as other templates or lead compounds derived from natural products, combinatorial libraries, and peptide substrate-based approaches (vide infra). Some examples of templates, which have been advanced to develop potent inhibitors of protein kinases, encompass functionalized derivatives of purines, pyrazolopyrimidines, pyrrolopyrimidines, pyridopyrimidines, pyridopyrimidinones, naphthyridinones, quinazolines, quinolines, dihydropyrimidoquinolines, indolinones, iminochromenes, and phenylaminopyrimidines.

Indeed, the chemical diversity of inhibitors of Src kinase illustrates the tremendous scope of template variation as well as the potential to develop potent and selective small-molecules relative to targeting the ATP- or peptide substrate-binding sites (Figures 11 and 12). Noteworthy examples of Src kinase or SFK inhibitors include purine analogs [NVP-AAK980 (75) and AP23137 (76)], pyrazolopyrimidine analogs [PP1 and PP2 (77)], pyrrolopyrimidine analogs (CGP-76775 [78] and CGP76030 (79)], pyridopyrimidine analogs [PD-089828 and PD$161570(80-82)]$, cyanoquinoline analogs $(83,84)$, indolinone analogs [SU6656 (85)], phenylaminopyrimidine analogs (86), natural products [staurosporine (59) and herbimycin (87)], combinatorial library-derived small molecules (88), and peptide substrate-based analogs (89).
The purine analog NVP-AAK980 is a potent inhibitor of Src kinase and effects anti-resorptive activity in vivo (75). Similarly, the purine analog AP23137 is a potent inhibitor of Src and has been shown to be highly selective for Src and SFKs as well as effective in several cancer cell lines (76). It is interesting that purinebased inhibitors having 2,6,9-trisubstitutions have been described previously as potent and selective inhibitors of CDKs (e.g., CDK2 inhibitor purvalanol B; vide infra) (65). The pyrazolopyrimidine analogs PP1 and PP2 have been described as potent inhibitors of Src-family kinases (e.g., Lck kinase) with marked selectivity versus ZAP-70 kinase, JAK2, EGFR kinase, and PKA (77). X-ray structures of Lck tyrosine kinase-PP2 and Hck tyrosine kinase-PP1 complexes have been determined $(59,60)$. The pyrrolopyrimidine analogs CGP-76775 and CGP-76030 have

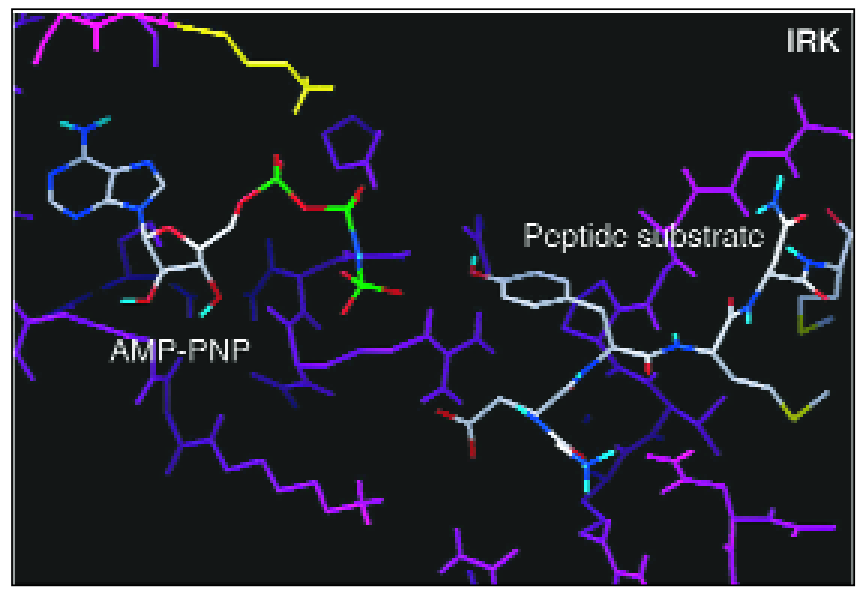

Figure 7. The X-ray structure of insulin receptor kinase (active conformation) complexed with both AMP-PNP (a nonhydrolyzable ATP analog) and peptide substrate to provide the first molecular map of a tyrosine protein kinase in this regard (62).

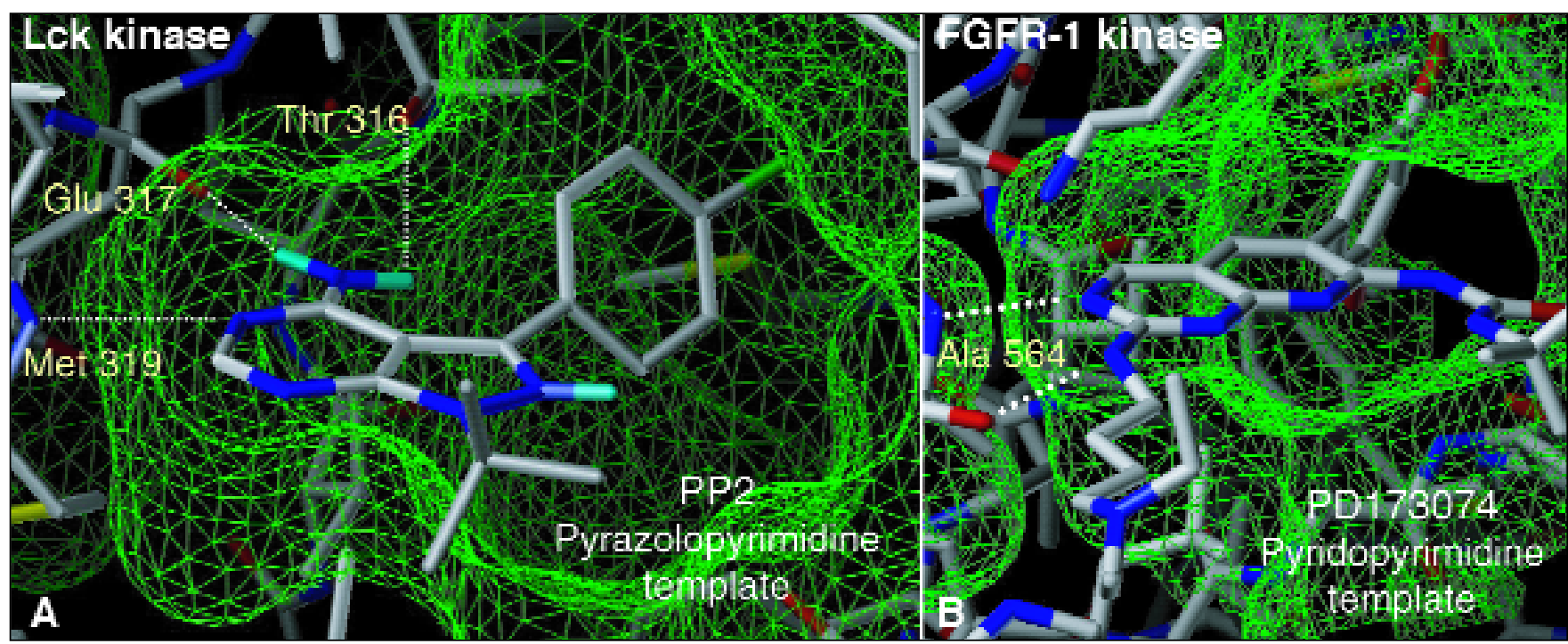

Figure 8. Two X-ray structures of tyrosine kinases complexed with ATP binding site inhibitors. (A) Lck kinase complexed with PP2, a pyrazolopyrimidine analog (59). (B) FGFR1 kinase complexed with PD173074, a pyridopyrimidine analog (63). Both cases illustrate H-bonding interactions with the ATP binding site as known to exist for ATP, as well as hydrophobic group interactions of each inhibitor with its respective hydrophobic specificity pocket of the protein kinases. In each case, the ATP binding site is represented by a green colored Connolly surface. 


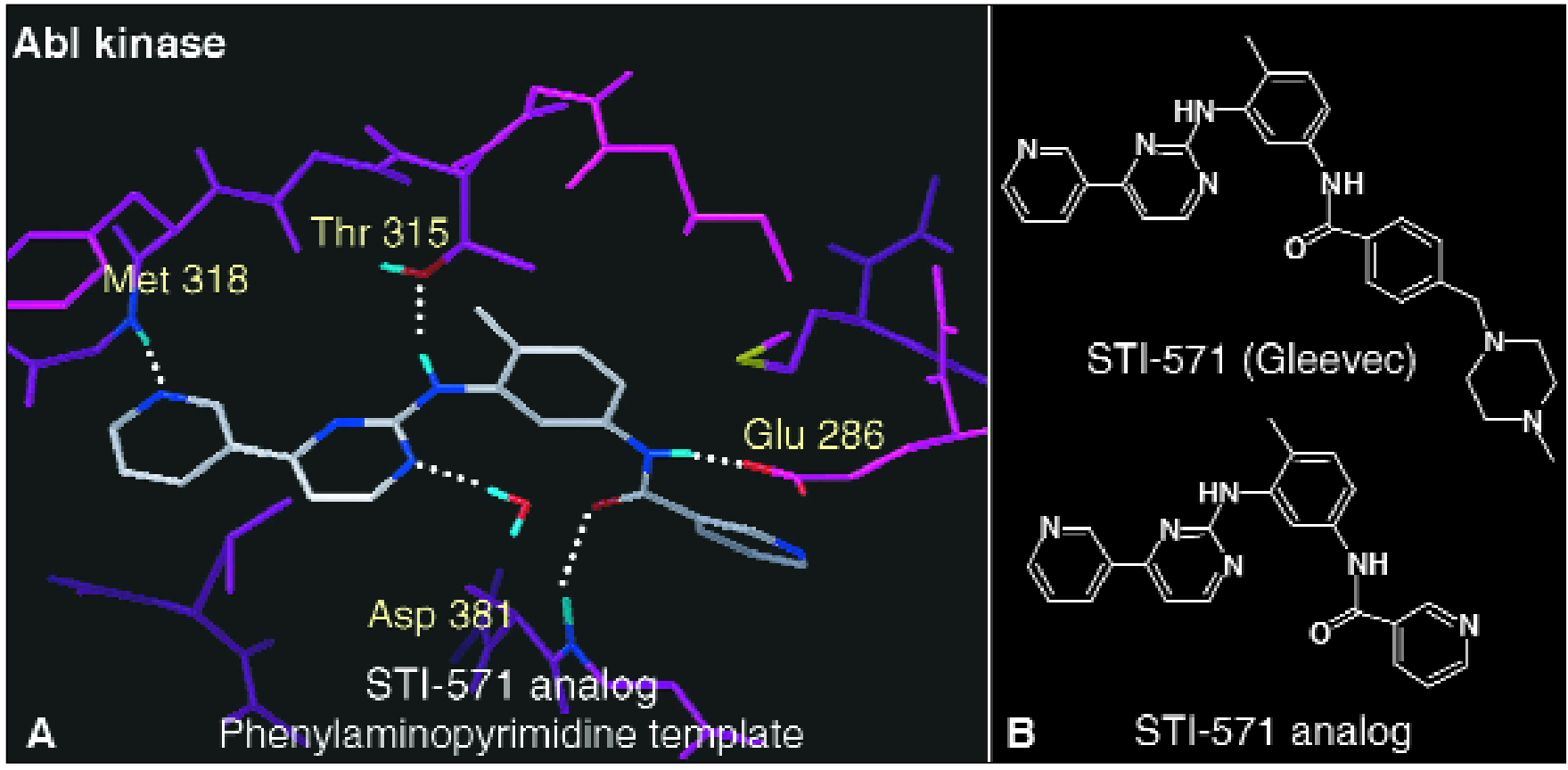

Figure 9. The X-ray structure of Abl kinase complexed with a Gleevec (STI-571) analog (68). (A) The binding of the STI-571 analog to an allosteric binding site of Abl kinase and showing the significant $\mathrm{H}$-bonding interactions. (B) Chemical structures of Gleevec and its analog.

been described as potent inhibitors of Src tyrosine kinase with selectivity relative to a number of protein kinases (e.g., EGFR kinase, v-Abl kinase, Cdc2 kinase, and Lck kinase) as well as in vivo activity in animal models of osteoporosis $(78,79)$. The pyridopyrimidine analogs PD-089828 and PD-161570 have been de- scribed as potent inhibitors of Src tyrosine kinase, but with marginal selectivity versus PDGFR, FGFR, and EGFR (80-82). A second-generation pyridopyrimidinone analog PD-180970 (vide supra; Figure 2) has been described as highly potent and selective inhibitor of Src tyrosine kinase as well as effecting potent inhibition of human colon tumor cell growth and colony-forming ability and inhibiting mitogen-stimulated thymidine incorporation in several cell lines (82). The cyanoquinoline analog (Figure 12) has been described as a highly potent inhibitor of Src tyrosine kinase (56), and this series of compounds has been shown to effect inhibition of proliferation in an Srctransfected fibroblast cell line $(83,84)$. The indolinone analog SU6656 has been described as a potent inhibitor of Src tyrosine kinase as well as SFKs (e.g., Lck, Fyn, and Yes kinases) (85). Furthermore, SU6656 was found to inhibit PDGF-stimulated DNA synthesis and Myc induction in a fibroblast cell line. The phenylaminopyrimidine analog (Figure 12) has been described as a relatively potent inhibitor of Src tyrosine kinase, albeit without selectivity versus $\mathrm{Abl}$ and EGFR tyrosine kinases (86). The natural product staurosporine is a potent

Figure 10. Chemical diversity of some known protein kinase inhibitors. Each template is illustrated as a generic structure with possible functional group elaboration. 
inhibitor of Lck kinase and Lck-mediated substrate phosphorylation and signal transduction in T cells (87). Novel small-molecule inhibitors of Src kinase have been discovered using combinatorial library-based strategies as exemplifed by a lead compound (Figure 12) showing high potency and exceptional selectivity versus other SFKs (e.g., Fyn, Lyn, and Lck kinases) (88). Finally, peptide substrate-based strategies have been advanced, as exemplified by a cyclic peptide (Figure 12), which is a potent inhibitor of Src kinase, as well as demonstrating marked selectivity for Src versus other SFKs (e.g., Lyn and Lck kinases) (89).

\section{PROTEIN KINASE INHIBITOR SMART DRUG DESIGN}

Protein kinase inhibitor drug design has been focused on a primary objective-to create a "smart" drug that is highly potent and selective to its therapeutic target as well as exhibiting significant efficacy in vivo and minimal toxicity (i.e., safe-acting). Such efforts have integrated molecular, cellular and in vivo disease model testing to identify promising lead compounds. Biological selectivity is considered a critical property to achieve an advantage of efficacy or toxicity properties in vivo. Scientists from ARIAD Pharmaceuticals (Cambridge, MA, USA) have established pioneering chemistry strategies to tackle the challenges of biological selectivity through the development of a small-molecule ARIAD therapeutics (SMART) drug design technology platform (Figure 13). In essence, the SMART drug design technology integrates 3D structural biology, molecular modeling, virtual screening, and other in silico drug design tools, chemoinformatics, and synthetic chemistry with significant analysis of the intellectual property of molecules of interest to both generate and optimize novel lead compounds. Relative to Src kinase inhibitor drug discovery, two key strategies aimed towards achieving remarkable biological selectivities in vitro and in vivo have successfully exploited SMART drug design technology relative to molecular selectivity (i.e., protein kinase SMART drug design) and cellular selectivity (i.e., bone-targeting SMART drug design) as schematically illustrated in Figure 13. Src kinase selectivity (versus other protein kinases) is essential to advance promising lead compounds for cancer and bone diseases, and in certain cases ARIAD Pharmaceuticals Src kinase inhibitors have shown $>1000$ - to 100,000 -fold selectivity over a panel of many other protein kinases [e.g., AP23464 (76)]. Cellular selectivity has been achieved for Src kinase inhibitors (ARIAD Pharmaceuticals) developed for osteolytic bone metastasis, hypercalcemia, and osteoporosis by further modification of such compounds with bone-targeting functional groups [e.g., AP23451 (90)]. In retrospect, such SMART drug design technology applications evolved from significant conceptual and experimental efforts focused on Src inhibitors, including some key prototype $\mathrm{SH} 3, \mathrm{SH} 2$, and kinase inhibitors (vide infra) exemplifying proof-of-concept biological selectivities in vitro and in vivo.

An intriguing example of achieving remarkable Src kinase inhibitory potency and selectivity by exploiting the purine template of ATP and using 3D structure-based drug design is illus-

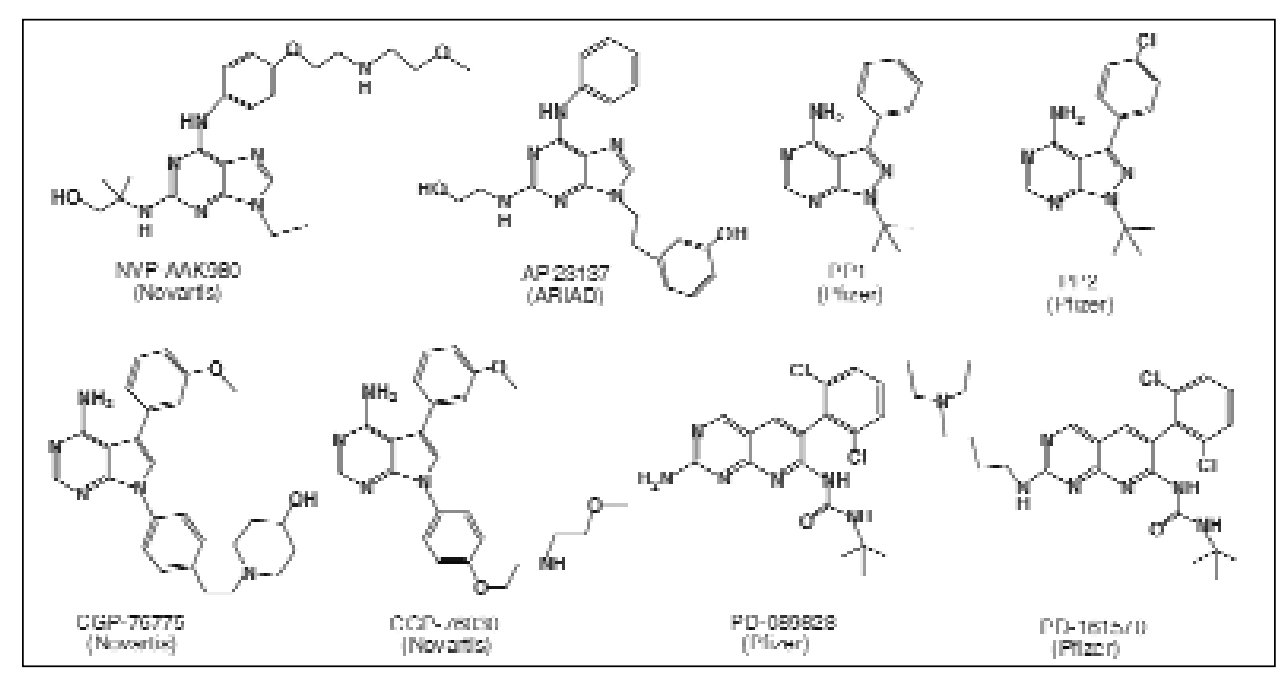

Figure 11. Some examples of Src kinase inhibitors illustrating known lead compounds representative of purine-, pyrazolopyrimidine-, pyrrolopyrimidine-, and pyridopyrimidine-based templates.

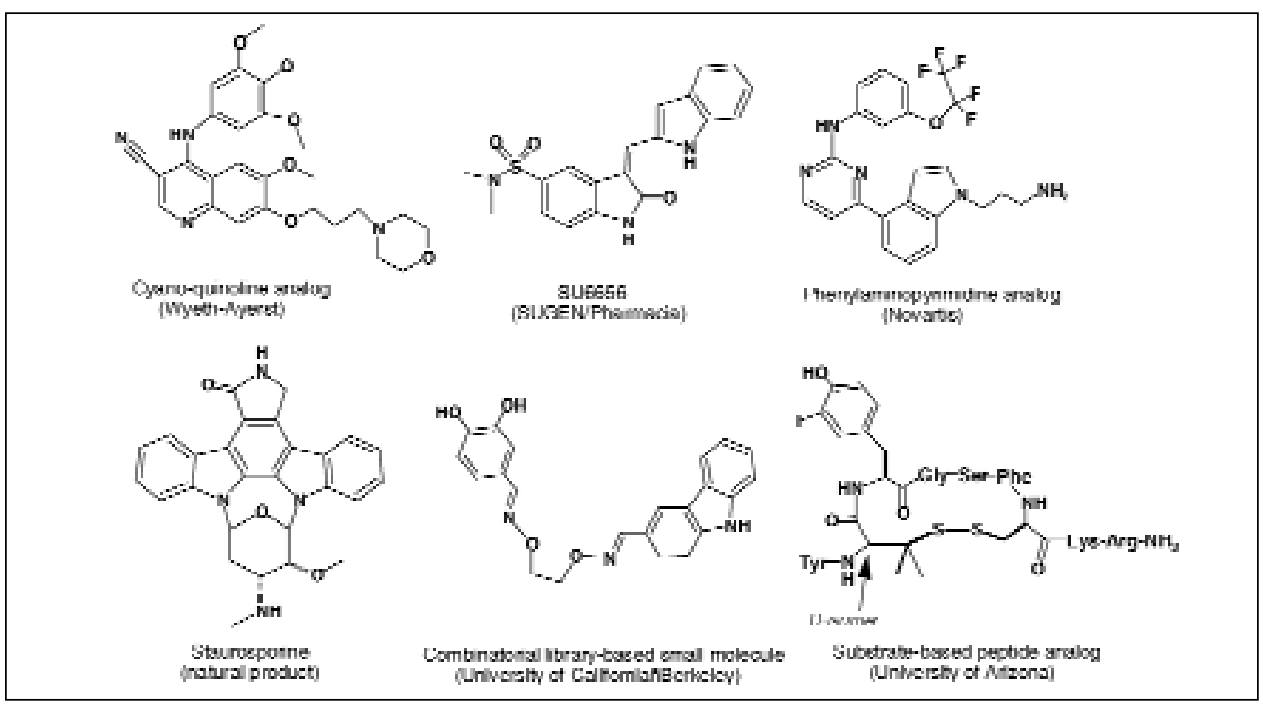

Figure 12. Some examples of Src kinase inhibitors illustrating known lead compounds representative of quinoline-, indolinone-, and phenylaminopyrimidine-based templates. Also, examples of natural product-, combinatorial library-, and peptide substrate-based inhibitors are shown. 


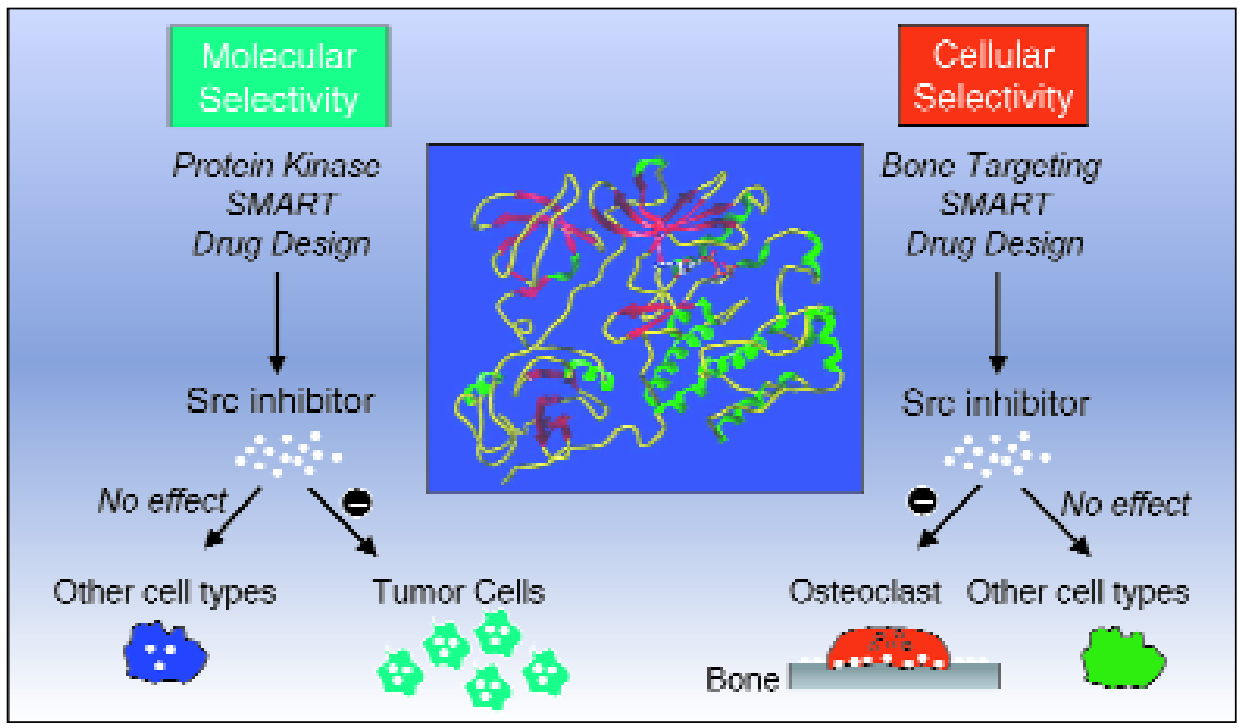

Figure 13. The SMART drug design technology platform as schematically illustrated to show both molecular and cellular selectivity strategies to create novel Src inhibitors. The SMART drug design technology platform exploits structure-based drug design as a critical component of an integrated drug discovey engine (see Figure 19) to enable the generation and/or optimization of lead compounds having extraordinary protein kinase (molecular) selectivity and/or bone-targeting (celluar) selectivity.

trated in Figure 14. Noteworthy is the highly potent and selective CDK2 inhibitor purvalanol B (Figure 14A), which was determined to bind quite differently to that of ATP while conserving key $\mathrm{H}$-bonds and taking advantage of a relatively small hydrophobic specificity pocket in CDK2 by its isopropyl group (65). In contrast, the Src kinase ATP binding site was predicted to accommodate a meta-hydroxyphenethyl group at the same position on the tri-substituted purine template as exemplified by AP23137 (Figure 14B). Most remarkably, the protein kinase selectivity properties of AP23137 were significant, including $>1000$-fold relative to CDK2 (an overall >100,000-fold selectivity reversal relative to purvalanol B). Other ATP binding site-targeted templates have been iteratively generated and optimized to achieve subnanomolar potent Src inhibitors with extraordinary protein kinase selectivity as well as promising cellular and in vivo

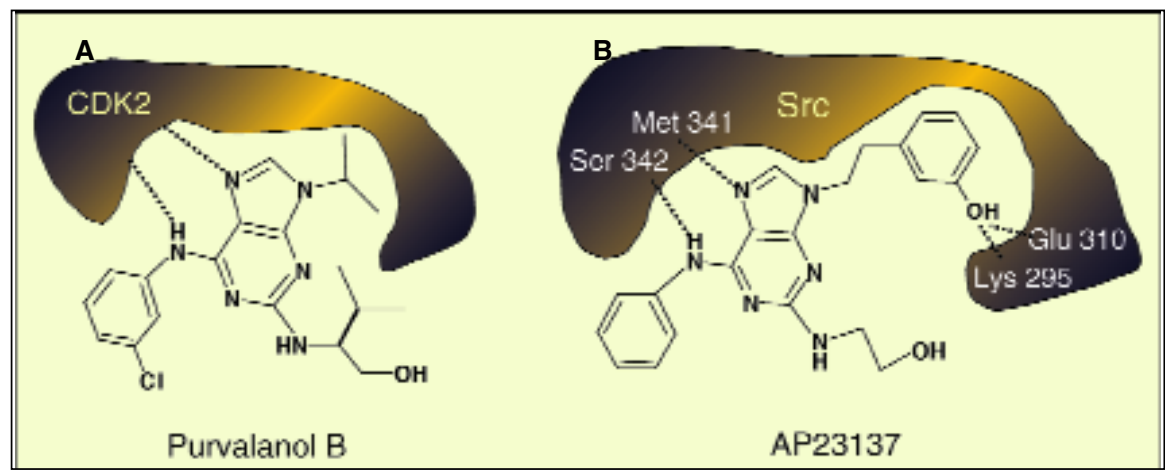

Figure 14. Schematic illustration of a purine-based template functionalized to provide potent and highly selective protein kinase inhibitors of CDK2 (65) and Src kinase (76), respectively. (A) Binding of purvalanol B to CDK2 showing conserved $\mathrm{H}$-bonding and interaction of its isopropyl group to a relatively smallsized hydrophobic pocket. (B) Binding of AP23137 to Src kinase showing conserved H-bonding and interaction of its hydroxyphenyethyl group to a relatively large-sized hydrophobic pocket (with further $\mathrm{H}$-bonding to the inhibitor's hydroxyl moiety). properties [e.g., AP23464 (89)].

The conceptual basis of the bonetargeting SMART drug design, which potentially may be exploited for a wide range of therapeutic targets, was derived from Src drug discovery efforts focused on the noncatalytic domains (i.e., $\mathrm{SH} 3$ and $\mathrm{SH} 2$ ) relative to functional genomic studies on osteoclasts that implicated their critical role in signal transduction pathways for cellular activation and bone resorption. Of the two noncatalytic domains, the $\mathrm{Src} \mathrm{SH} 3$ has been extremely recalcitrant to the discovery of small-molecule inhibitors and, perhaps, the most significant achievement to date has been the combinatorial library-based peptidomimetic inhibitor (Figure 15), which has been described as a potent inhibitor of $\mathrm{Src} \mathrm{SH} 3$ binding, although it is not known if it possesses cellular activity (91). In contrast, the $\mathrm{Src} \mathrm{SH} 2$ domain has been successfully challenged by iterative structure-based drug design strategies resulting in a series of potent nonpeptide inhibitor ligands, including AP21733 and AP22408 (Figures 15 and 16) (92-94). Particularly noteworthy in the context of bone-targeting SMART drug design was AP22408, which incorporated a diphosphonoaryl-modified pTyr residue that conferred a new biological property to the molecule, namely that of exhibiting affinity to bind hydroxyapatite (mineral component of bone) and subsequent osteoclast-selective activities both in vitro and in vivo (92). In the case of AP22408, the modification of the pTyr residue by a novel bone-targeted pTyr mimic (Figure 15) addressed both the challenge of designing a nonhydrolyzable pTyr moiety as well as increasing the in vivo delivery of the $\mathrm{Src} \mathrm{SH} 2$ inhibitor to osteoclasts in bone tissue. A 3D molecular overlay of AP22408 with both AP21733 and the cognate phosphopeptide pTyr-Glu-Glu-Ile in their binding conformations illustrates how beautifully the bicyclic nonpeptide template of AP22408 interacts with the hydrophobic surface of the Src SH2 domain as well as the favorable interactions of its diphosphonoarylmodified pTyr moiety at the pTyr binding site (Figure 16).

Exploitation of the bone-targeting concept from the above $\mathrm{Src} \mathrm{SH} 2$ studies led to a significant breakthrough relative to the structure-based drug design of highly potent and osteoclast-selective bone-targeted Src kinase inhibitors (Figures 17 and 18) (95-97). For example, incorporation of bone-targeting moieties into purine, pyrrolopyrimidine, and pyridopyrimidine templates provided a prototype series of highly potent Src kinase inhibitors (Figure 
17). These lead compounds exhibited nanomolar potent inhibition of Src kinase and provided proof-of-concept towards the objective of achieving osteoclastselective antiresorptive activity in vitro as well as establishing a basis for subsequent studies to advance the first bone-targeted Src kinase inhibitors showing in vivo efficacy. The predicted binding of these bone-targeted purine, pyrrolopyrimidine, and pyridopyrimidine analogs is illustrated in Figure 18, and each may be also compared with ATP binding to Src kinase. Conserved $\mathrm{H}$-bonding interactions to Met-341 and Ser-342 are predicted to lock the varying templates into the adenine-binding pocket for ATP. In each case, a hydrophobic moiety provides favorable intermolecular interactions with the hydrophobic specificity pocket of the ATP binding site. Furthermore, for each inhibitor, the bone-targeting group was regiospecifically incorporated to take advantage of potential binding interactions or to simply avoid possible adverse intermolecular interactions at the ATP binding site of Src kinase.

\section{PROTEIN KINASE \\ INHIBITOR DRUG DISCOVERY: A FUTURE PERSPECTIVE}

The future of protein kinase inhibitor drug discovery is expected to be extraordinary relative to the plethora of protein kinases identified in the human genome as well as the increased knowledge of protein kinases relative to signal transduction pathways in cells and the relationship to diseases (e.g., cancer). The successful development of both Gleevec and Iressa provide precedence towards such opportunities. Ultimately, it is the molecule itself that must overcome the many challenges to advance to clinical testing, and for protein

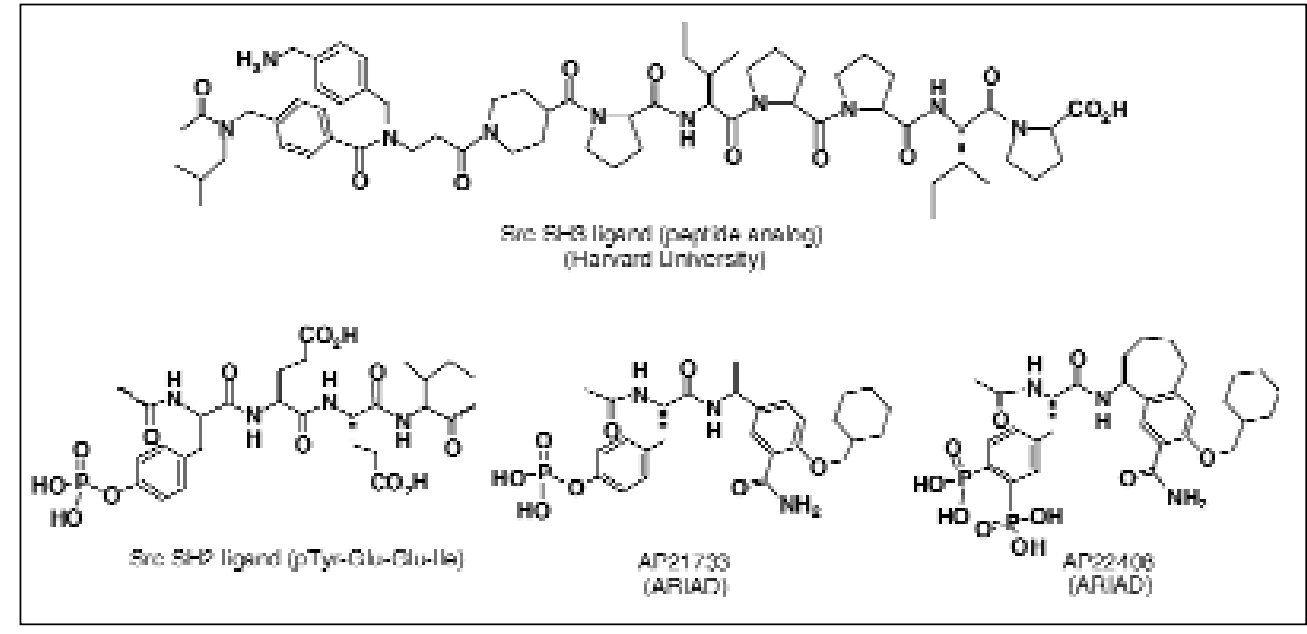

Figure 15. Some examples of peptidomimetic and nonpeptide inhibitors of Src SH3 and Src SH2, respectively.
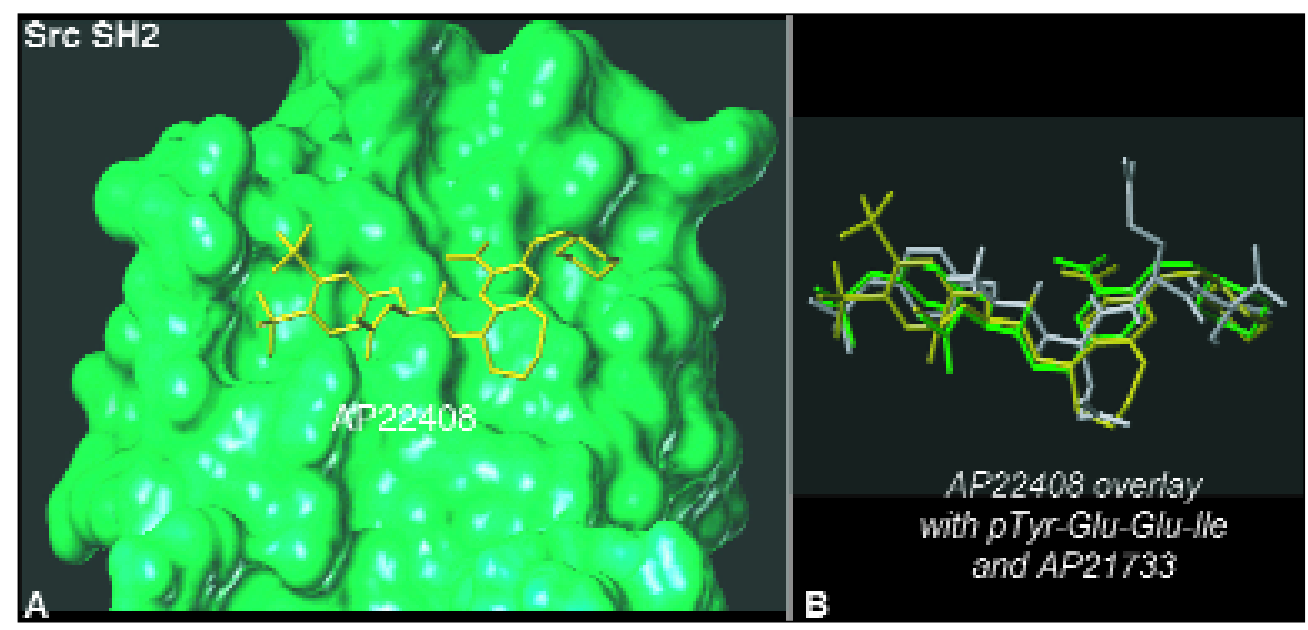

Figure 16. Comparative X-ray structure and 3D modeling studies of the Src SH2 domain and inhibitors, including nonpeptide ligands AP21733 (94) and AP22408 (92). (A) 3D model of the bone-targeted nonpeptide inhibitor AP22408 complexed with Src SH2 domain illustrating its molecular interactions with the protein. (B) 3D overlay of AP22408 with both AP21733 and the cognate phosphopeptide pTyr-Glu-Glu-Ile illustrating the novel bicyclic template (replacing Glu-Glu of the peptide) and novel bone-targeted diphosphonoaryl-modified pTyr mimic.

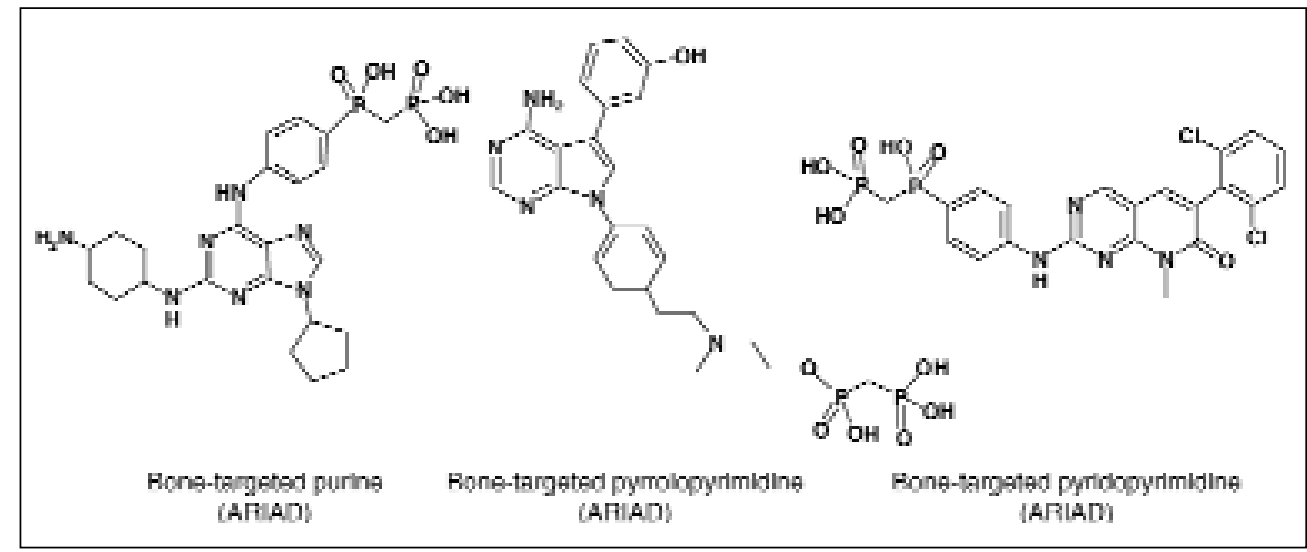

Figure 17. Prototype bone-targeted Src inhibitors illustrating purine-, pyrrolopyrimidine-, and pyridopyrimidinebased templates. 

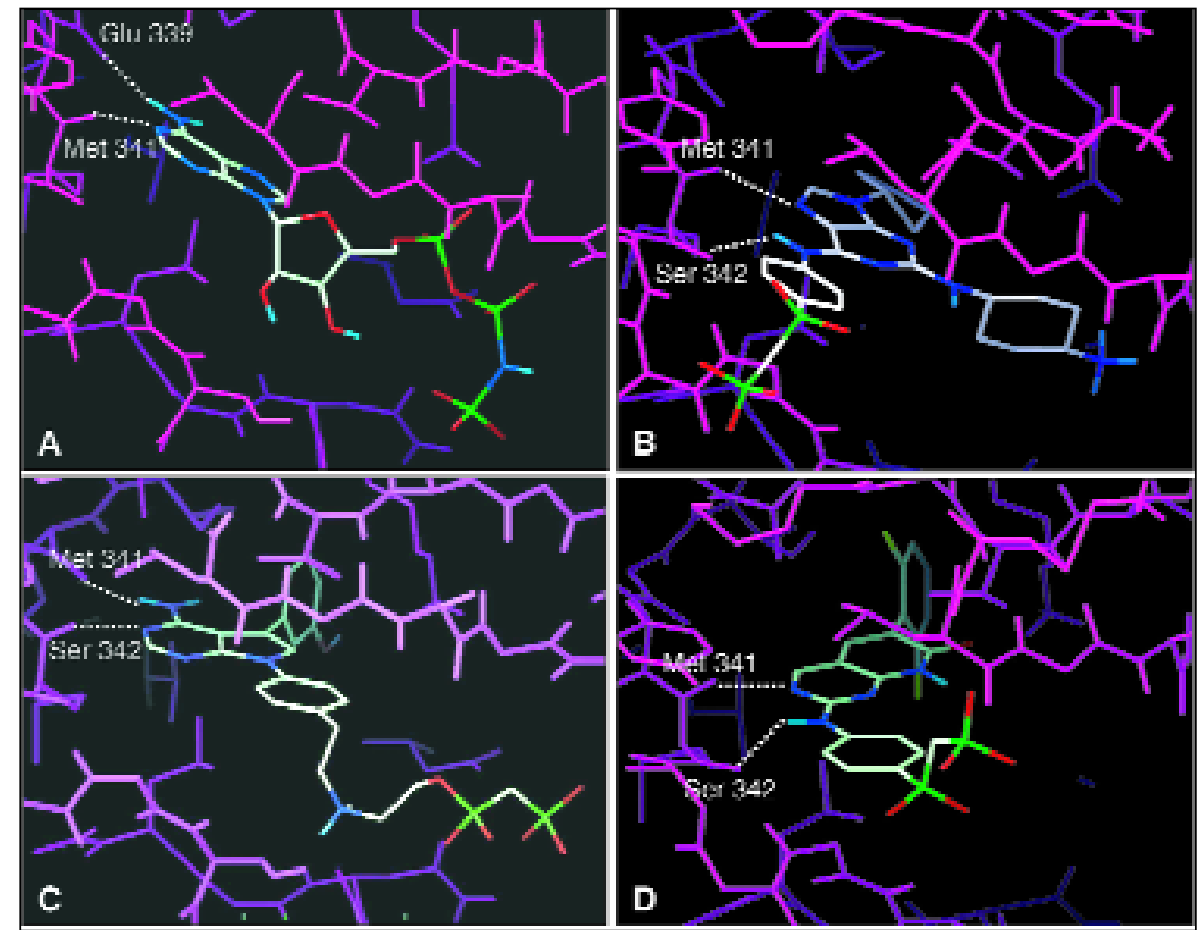

Figure 18. Comparative 3D molecular modeling studies on ATP and three different bone-targeted Src kinase inhibitors (95-97). (A) 3D molecular model of AMP-PNP complexed with Src kinase in its active conformation showing conserved $\mathrm{H}$-bonding to the adenine ring of the ATP analog. (B) 3D molecular model of a bone-targeted purine analog showing conserved H-bonding as well as interaction of its cyclopentyl group into the hydrophobic specificity pocket. (C) 3D molecular model of a bone-targeted pyrrolopyrimidine analog showing conserved $\mathrm{H}$-bonding as well as interaction of its hydroxyphenyl group into the hydrophobic specificity pocket. (D) 3D molecular model of a bone-targeted pyridopyrimidine analog showing conserved $\mathrm{H}$ bonding as well as interaction of its dichlorophenyl group into the hydrophobic specificity pocket. In each case, a bone-targeting group was regiospecifically incorporated to potentially increase binding interactions or, more simply, to minimize adverse intermolecular interactions with Src kinase. kinase inhibitors, this includes biological selectivity in vitro and in vivo. In some cases, molecular selectivity may include more than one protein kinase that is desirable to be inhibited to effect significant modulation of cellular activities. Certainly, the opportunity to exploit drug design strategies to advance dual or multiple protein kinase-targeted inhibitors is possible. In fact, there is significant literature already providing a database of such biological selectivity information that has been created as the result of in vitro profiling of various protein kinase inhibitors as part of many drug discovery campaigns. Nevertheless, 3D structure-based drug design will continue to provide a key strategy to generate and/or optimize promising lead compounds (98), and it is expected that future protein kinase drug discovery will exploit a variety of high-powered in silico tools to computationally visualize, analyze, and probe the molecular properties and interactions of novel small-molecule inhibitors with their desired therapeutic target(s). Indeed, integration of such in silico tools (e.g., molecular modeling and virtual screening) with structural biology (e.g., X-ray and/or NMR structures of a lead compound complexed with its therapeutic target), chemical synthesis (e.g., combinatorial, medicinal, and natural product), biological screening (e.g., in vitro and in vivo therapeutic target assays), chemoinformatics, and bioinformatics provides the essential parts of such a protein kinase inhibitor drug discovery engine (Figure 19). In the context of this review, the evolution of protein kinase inhibitors from "genes to drugs" will likely be one of the most fascinating epochs in drug discovery and, hopefully, will make a dramatic impact in the treatment of disease. Certainly, this is the driving force underlying the SMART drug design technology efforts at ARIAD Pharmaceuticals, which are currently focused on the development of novel protein kinase inhibitor drugs (http://www.ariad.com).
Figure 19. An integrated drug discovery engine for protein kinase drug discovery. Key components of this drug discovery engine include structural biology, drug design, chemistry, biology, chemoinformatics, and bioinformatics. 


\section{REFERENCES}

1.Sawyer, T., B. Boyce, D. Dalgarno, and J. Iuliucci. 2001. Src inhibitors: genomics to therapeutics. Expert Opin. Investig. Drugs 10:1327-1344.

2.Frame, M.C. 2002. Src in cancer: deregulation and consequences for cell behaviour. Biochim. Biophys. Acta 1602:114-130.

3.Sawyer, T.K. Cancer metastasis: therapeutic targets and drug discovery. Expert Opin. Investig. Drugs (In press).

4.McMahon, G., L. Sun, C. Liang, and C. Tang. 1998. Protein kinase inhibitors: structural determinants for target specificity. Curr. Opin. Drug Discov. Devel. 1:131-146.

5.Strawn, L.M. and L.K. Shawver. 1998. Tyrosine kinases in diseases. Overview of kinase inhibitors as therapeutic agents and current drugs in clinical trials. Exp. Opin. Invest. Drugs 7:533-573.

6.Traxler, P. 1998. Tyrosine kinase inhibitors in cancer treatment (part II). Exp. Opin. Ther. Patents 8:1599-1628.

7.Lawrence, D.S. and J. Niu. 1998. Protein kinase inhibitors: the tyrosine-specific kinases. Pharmacol. Ther. 77:81-114.

8.Bridges, A.J. 1999. The rationale and strategy used to develop a series of highly potent, irreversible, inhibitors of the epidermal growth factor receptor family of tyrosine kinases. Curr. Med. Chem. 6:825-843.

9.Toledo, L.M., N.B. Lydon, and D. Elbaum. 1999. The structure-based design of ATP-site directed protein kinases. Curr. Med. Chem. 6:775-805.

10.Stover, D.R., N.B. Lydon, and J.J. Nunes. 1999. Recent advances in protein kinase inhibition: current molecular scaffolds used for inhibitor synthesis. Curr. Opin. Drug Discov. Devel. 2:274-285.

11.Sedlacek, H.H. 2000. Kinase inhibitors in cancer therapy. Drugs 59:435-476.

12.Tsatsanis, C. and D.A. Spanidos. 2000. The role of oncogenic kinases in human cancer. Int. J. Mol. Med. 5:583-590.

13.Dalgarno, D.C., C.A. Metcalf, W.C. Shakespeare, and T.K. Sawyer. 2000 Signal transduction drug discovery: targets, mechanisms, and structure-based design. Curr. Opin. Drug Discov. Devel. 3:549-564.

14.Dumas, J. 2001. Protein kinase inhibitors: emerging pharmacophores $1997-$ 2000. Exp. Opin. Ther. Patents 11:405-429.

15.Fabbro, D., S. Ruetz, E. Buchdunger, S.W. Cowan-Jacob, G. Fendrich, J. Liebetanz, et al. 2002. Protein kinases as targets for anticancer agents: from inhibitors to useful drugs. Pharmacol. Ther. 93:79-98.

16.Cohen, P. 2002. Protein kinases-the major drug targets of the twenty-first century? Nat. Rev. Drug Discov. 1:309-315.

17.Brunelleschi, S., L. Penesgo, M.M. Santoro, and G. Gaudino. 2002. Receptor tyrosine kinases as target for anti-cancer therapy. Curr. Pharm. Des. 8:19591972.

18.Drevs, J., M. Medinger, C. Schmidt-Gersbach, R. Weber, and C. Unger. 2003. Receptor tyrosine kinases: the main targets for new anticancer therapy. Cur. Drug Targets 4:113-121.

19.Metcalf, C.A., III, M.R. van Schravendijk, D.C. Dalgarno, and T.K. Sawyer. 2002. Targeting protein kinases for bone disease: discovery and development of Src inhibitors. Curr. Pharm. Des. 8:2049-2075.

20.Dancey, J. and E.A. Sausville. 2003. Issues and progress with protein kinase inhibitors for cancer treatment. Nat. Rev. Drug Discov. 2:296-313.

21.International Human Genome Consortium. 2001. Initial sequencing and analysis of the human genome. Nature 409:860-921.

22.Venter, J.C., M.D. Adams, E.W. Myers, P.W. Li, et al. 2001. The sequence of the human genome. Science 291:1304-1351.

23.Manning G., D.B. Whyte, R. Martinez, T. Hunter, and S. Sudarsanam. 2002. The protein kinase complement of the human genome. Science 298:1912-1934.

24.Peggs K. and S. Mackinnon. 2003. Imatinib mesylate-the new gold standard for treatment of chronic myeloid leukemia. N. Engl. J. Med. 348:1048-1050.

25.Druker, B.J. 2003. Imatinib alone and in combination for chronic myeloid leukemia. Semin. Hematol. 40:50-58.

26.Ottmann, O.G., B. Wassmann, and D. Hoelzer. 2002. Imatinib for relapsed BCR/ABL positive leukemias. Ann. Hematol. 81(Suppl 2):S36-S37.

27.Wakeling, A.E., S.P. Guy, J.R. Woodburn, S.E. Ashton, B.J. Curry, A.J. Barker, and K.H. Gibson. 2002. ZD1839 (Iressa): an orally active inhibitor of epidermal growth factor signaling with potential for cancer therapy. Cancer Res. 62:49-54.

28.Wakeling, A.E. 2002. Epidermal growth factor receptor tyrosine kinase inhibitors. Curr. Opin. Pharmacol. 2:382-387.

29.Ranson, M., W. Mansoor, and G. Jayson. 2002. ZD1839 (IRESSA): a selective EGFR-TK inhibitor. Expert Rev. Anticancer Ther. 2:161-168.

30.Thomas, S.M. and J.S. Brugge. 1997. Cellular functions regulated by Src fam- ily kinases. Annu. Rev. Cell. Dev. Biol. 13:513-609.

31.Biscardi, J.S., D.A. Tice, and S.J. Parsons. 1999. c-Src, receptor tyrosine kinases, and human cancer. Adv. Cancer Res. 76:61-119.

32.Susa, M., M. Missbach, and J. Green. 2000. Src inhibitors: drugs for the treatment of osteoporosis, cancer or both? Trends Pharmacol. Sci. 21:489-495.

33.Susa, M. and A. Teti. 2000. Tyrosine kinase Src inhibitors: potential therapeutic applications. Drug News Perspect. 13:169-175.

34.Soriano, P., C. Montgomery, R. Geske, and A. Bradley. 1991. Targeted disruption of the c-Src proto-oncogene leads to osteopetrosis in mice. Cell 64:693702

35.Lowe, C., T. Yoneda, B.F. Boyce, H. Chen, et al. 1993. Osteopetrosis in Srcdeficient mice is due to an autonomous defect of osteoclasts. Proc. Natl. Acad. Sci. USA 90:4485-4489.

36.Schwartzberg, P.L., L. Xing, O. Hoffmann, et al. 1997. Rescue of osteoclast function by transgenic expression of kinase-deficient Src in src-/- mutant mice. Genes Dev. 11:2835-2844.

37.Marzia, M., N.A. Sims, S. Voit, S. Migliacco, et al. 2000. Decreased c-Src expression enhances osteoblast differentiation and bone formation. J. Cell Biol. 151:311-320.

38.Amling, M., I. Neff, M. Priemel, A.F. Schilling, et al. 2000. Progressive increase in bone mass and development of odontomas in aging osteopetrotic csrc-deficient mice. Bone 27:603-610.

39.Lowell, C.A. and P. Soriano. 1996. Knockouts of Src-family kinases: stiff bones, wimpy $\mathrm{T}$ cells, and bad memories. Genes Dev. 10:1845-1857.

40.Benistant, C., J.-F. Bourgaux, H. Chapuis, N. Mottet, et al. 2001. The $\mathrm{COOH}$-terminal Src kinase Csk is a tumor antigen in human carcinoma. Cancer Res. 61:1415-1420.

41.Bjorge, J.D., A. Pang, and D.J. Fujita. 2000. Identification of protein-tyrosine phosphatase $1 \mathrm{~B}$ as the major tyrosine phosphatase activity capable of dephosphorylating and activating c-Src in several human breast cancer cell lines. J. Biol. Chem. 275:41439-41446.

42.Wilson, L.K., D.K. Luttrell, J.T. Parsons, and S.J. Parsons. 1989. pp60c-src tyrosine kinase, myristylation, and modulatory domains are required for enhanced mitogenic responsiveness to epidermal growth factor seen in cells overexpressing c-Src. Mol. Cell. Biol. 9:1536-1544.

43.Maa, M.-C., T.H. Leu, D.J. McCarley, R.C. Schatzman, and S.J. Parsons. 1995. Potentiation of epidermal growth factor receptor-mediated oncogenesis by c-Src: implications for the etiology of multiple human cancers. Proc. Natl. Acad. Sci. USA 92:6981-6985.

44.Mao, W., R. Irby, D. Coppola, L. Fu, et al. 1997. Activation of c-Src by receptor tyrosine kinases in human colon cancer cells with high metastatic potential. Oncogene 15:3083-3090.

45.Turkson, J., T. Bowman, R. Garci, E. Caldenhove, et al. 1998. STAT3 activation by Src induces specific gene regulation and is required for cell transformation. Mol. Cell. Biol. 18:2545-2552.

46.Staley, C.A., N.U. Parikh, and G.E. Gallick. 1997. Decreased tumorigenicity of a human colon carcinoma cell line by an antisense expression vector specific for c-Src. Cell Growth Differ. 8:269-274.

47.Ellis, L.M., C.A. Staley, W. Liu, R.Y. Fleming, et al. 1998. Downregulation of vascular endothelial growth factor in a human colon carcinoma cell line transfected with an antisense expression vector specific for c-Src. J. Biol. Chem. 273:1052-1057.

48.Irby, R.B., W. Mao, D. Coppola, J. Kang, et al. 1999. Activating SRC mutation in a subset of advanced human colon cancers. Nat. Genet. 21:187-190.

49.Egan, C., A. Pang, D. Durda, H.-C. Cheng, et al. 1999. Activation of Src in human breast tumor cell lines: elevated levels of phosphotyrosine phosphatase activity that preferentially recognizes the Src carboxy terminal negative regulatory tyrosine 530. Oncogene 18:1227-1237.

50.Verbeek, B.S., T.M. Vroom, S.S. Adriaansen-Slot, A.E. Ottenhoff-Kalif, et al 1996. c-Src protein expression is increased in human breast cancer. An immunohistochemical and biochemical analysis. J. Pathol. 180:383-388.

51.Talamonti, M.S., M.S. Roh, S.A. Curley, and G.E. Gallick. 1993. Increase in activity and level of pp60c-src in progressive stages of human colorectal cancer. J. Clin. Invest. 91:3-60.

52.Van Oijen, M.G., C.T. Rijkseng, F.W. ten Broek, and P.J. Slootweg. 1998 Overexpression of c-Src in areas of hyperproliferation in head and neck cancer premalignant lesions and benign mucosal disorders. J. Oral Pathol. Med. 27:147-152.

53.Lutz, M.P., I.B. Esser, B.B. Flossmann-Kast, R. Vogelmann, et al. 1998. Overexpression and activation of the tyrosine kinase Src in human pancreatic carcinoma. Biochem. Biophys. Res. Commun. 243:503-508.

54.Cohen, G.B., R. Ren, and D. Baltimore. 1995. Modular binding domains in 
signal transduction. Cell 80:237-248.

55.Pawson, T. 1995. Protein modules and signalling networks. Nature 373:573580

56.Dalgarno, D.C., M.C. Botfield, and R.J. Rickles. 1997. SH3 domains and drug design: ligands, structure, and biological function. Biopolymers (Peptide Sci.) 43:383-400

57.Sawyer, T.K., R.S. Bohacek, D.C. Dalgarno, C.J. Eyermann, N. Kawahata, C.A. Metcalf, III, et al. 2002. SRC homology-2 inhibitors: peptidomimetic and nonpeptide. Mini Rev. Med. Chem. 2:475-488

58.Xu, W., A. Doshi, M. Lei, M. Eck, and S.C. Harrison. 1999. Crystal structures of c-Src reveal features of its autoinhibitory mechanism. Mol. Cell 3:629-636.

59.Zhu, X., J.L. Kim, J.R. Newcomb, P.E. Rose, D.R. Stover, et al. 1999. Structural analysis of the lymphocyte-specific Lck in complex with non-selective and Src family-selective kinase inhibitors. Structure 7:651-661.

60.Schindler, T., F. Sichieri, A. Pico, A. Gazit, et al. 1999. Crystal structure of Hck in complex with Src family-selective tyrosine kinase inhibitor. Mol. Cell 3:639-648.

61.Lamers, M.B., A.A. Antson, R.E. Hubbard, R.K. Scott, and D.H. Williams. 1999. Structure of C-terminal Src kinase (CSK) in complex with staurosporine. J. Mol. Biol. 28:713-725.

62.Hubbard, S.R. 1997. Crystal structure of the activated insulin receptor tyrosine kinase in complex with peptide substrate and ATP analog. EMBO J. 16:55725581.

63.Mohammadi, M., G. McMahon, L. Sun, P.C. Tang, et al. 1997. Structures of the tyrosine kinase domain of fibroblast growth factor receptor in complex with inhibitors. Science 276:955-960.

64.McTigue, M.A., J.A. Wilkersham, C. Pinko, R.E. Showalter, et al. 1999. Crystal structure of the kinase domain of human vascular endothelial growth factor receptor 2: a key enzyme in angiogenesis. Structure Fold. Des. 7:319-330.

65.Gray, N.S., L. Wodicka, A.-M. Thunnissen,T.C. Norman, S. Kwon, et al. 1998. Exploiting chemical libraries, structure, and genomics in the search for kinase inhibitors. Science 281:533-538.

66.Legravend, M., P. Tunnah, M. Noble, P. Ducrot, et al. 2002. Cyclin-dependent kinase inhibition by new C-2 alkynylated purine derivatives and molecular structure of a CDK2-inhibitor complex. J. Med. Chem. 43:1282-1292.

67.Dreyer, M.K., D.R. Borcherding, J.A. Dumont, N.P. Peet, et al. 2001. Crystal structure of human cyclin-dependent kinase 2 in complex with the adenine-derived inhibitor H717. J. Med. Chem. 44:524-530.

68.Schindler, T., W. Bornmann, P. Pellicena, W.T. Miller, et al. 2002. Structural mechanism for STI-571 inhibition of Abelson tyrosine kinase. Science 289:1938-1942.

69.Shah, K., Y. Liu, C. Deirmengian, and K.M. Shokat. 1997. Engineering unnatural nucleotide specificity for Rous sarcoma virus tyrosine kinase to uniquely label is direct substrates. Proc. Natl. Acad. Sci. USA 94:3565-3570.

70.Bishop, A.C., K. Shah, Y. Liu, L. Witucki, et al. 1998. Design of allele-specific inhibitors to probe protein kinase signaling. Curr. Biol. 8:257-266.

71.Bishop, A.C., C.-Y. Kung, K. Shah, L. Witucki, et al. 1999. Generation of monospecific nanomolar tyrosine kinase inhibitors via a chemical genomics approach. J. Am. Chem. Soc. 121:627-631.

72.Tong, L., S. Pav, D.M. White, S. Rogers, K.M. Crane, C.L. Cywin, M.L. Brown, and C.A. Pargellis. 1997. A highly specific inhibitor of human p38 MAP kinase binds in the ATP pocket. Nat. Struct. Biol. 4:311-316.

73.Chen, J. and Y. Fang. 2002. A novel pathway regulating the mammalian target of rapamycin (mTOR) signaling. Biochem. Pharmacol. 64:1071-1077.

74.Huang, S. and P.J. Houghton. 2002. Inhibitors of mammalian target of rapamycin as novel antitumor agents: from bench to clinic. Curr. Opin. Investig. Drugs 3:295-304.

75.Missbach, M., E. Attman, and M. Susa. 2000. Tyrosine kinase inhibition in bone metabolism. Curr. Opin. Drug Discov. 3:541-548

76.Metcalf, C., III, Y. Wang, W. Shakespeare, R. Sundaramoorthi, T. Keenan, D. Dalgarno, et al. 2003. Discovery of potent and selective Src inhibitors and their development as antitumor and antimetastatic agents. Proc. AACR 44:A1716.

77.Hanke, J.H., J.P. Gardner, R.L. Dow, P.S. Changelian, et al. 1996. Discovery of a novel, potent, and Src family-selective tyrosine kinase inhibitor. J. Biol. Chem. 271:695-701.

78.Missbach, M., M. Jeschke, J. Feyer, K. Muller, et al. 1999. A novel inhibitor of the tyrosine kinase Src suppresses phosphorylation of its major cellular substrates and reduces bone resorption in vitro and in rodent models in vivo. Bone 24:437-449.

79.Kneissel, M., R. Gamse, M. Missbach, L. Wilder, et al. 1999. Tyrosine kinase Src inhibitor CGP 76030 suppresses rapid bone loss induced by retinoic acid in rats. Calcif. Tissue Int. 64(Suppl 1):S75.
80.Hamby, J.M., C.J.C. Connolly, M.C. Schroeder, R.T. Winters, et al. 1997. Structure-activity relationships for a novel series of pyrido[2,3-d]pyrimidine tyrosine kinase inhibitors. J. Med. Chem. 40:2296-2303.

81.Batley, B.L., A.M. Doherty, J.M. Hamby, G.H. Lu, P. Keller, T.K. Dahring, O. Hwang, K. Crickard, and R.L. Panek. 1998. Inhibition of FGF-1 receptor tyrosine kinase activity by PD 161570, a new protein-tyrosine kinase inhibitor. Life Sci. 62:143-150.

82.Kraker, A.J., B.G. Hartl, A.M. Amar, M.R. Barvian, et al. 2000. Biochemical and cellular effects of c-Src kinase-selective pyrido[2,3-d]pyrimidine tyrosine kinase inhibitors. Biochem. Pharmacol. 60:885-898.

83.Wang, Y.D., K. Miller, D.H. Boschelli, F. Ye, et al. 2000. Inhibitors of Src tyrosine kinase: the preparation and structure-activity relationship of 4-anilino-3cyanoquinolines and 4-anilinoquinazolines. Bioorg. Med. Chem. Lett. 10:2477-2480.

84.Boschelli, D.H., Y.D. Wang, F. Ye, B. Wu, et al. 2001. Synthesis and Src kinase inhibitory activity of a series of 4-phenylamino-3-quinolinecarbonitriles. J. Med. Chem. 44:822-833.

85.Blake, R.A., M.A. Broome, X. Liu, J. Wu, et al. 2000. SU6656, a selective Src family kinase inhibitor used to probe growth factor signaling. Mol. Cell. Biol. 20:9018-9027.

86.Zimmerman, J., E. Buchdunger, H. Mett, T. Meyer, and N.B. Lydon. 1997. Potent and selective inhibitors of the Abl-kinase: phenylaminopyrimidine (PAP) derivatives. Bioorg. Med. Chem. Lett. 7:187-192.

87.Yoneda, T., C. Lowe, C.-H. Lee, G. Gutierra, et al. 1993. Herbimycin A, a pp60c-src tyrosine kinase inhibitor, inhibits osteoclastic bone resorption in vitro and hypercalcemia in vivo. J. Clin. Invest. 91:2791-2795.

88.Maly, D.J., I.C. Choong, and J.A. Ellman. 2000. Combinatorial target-guided ligand assembly: identification of potent subtype-selective c-Src inhibitors. Proc. Natl. Acad. Sci. USA 97:2419-2424.

89.Alfaro-Lopez, J., W. Yuan, B.C. Phan, J. Kamath, et al. 1998. Discovery of a novel series of potent and selective substrate-based inhibitors of pp60c-src protein tyrosine kinase: conformational and topographical constraints in peptide design. J. Med. Chem. 41:2252-2260.

90.Shakespeare, W., Y. Wang, C. Metcalf, R. Sundaramoorthi, T. Keenan, R. Bohacek, et al. 2003. Development of a novel bone-targeted Src tyrosine kinase inhibitor AP23451 having potent activity in an animal model of osteolytic bone metastasis. Proc. AACR 44:A3871.

91.Feng, S., T.M. Kapoor, F. Shirai, A.P. Combs, and S.L. Schreiber. 1996. Molecular basis for the binding of $\mathrm{SH} 3$ ligands with non-peptide elements identified by combinatorial synthesis. Chem. Biol. 3:661-670.

92.Shakespeare, W.C., M. Yang, R. Bohacek, F. Cerasoli, et al. 2000. Structurebased design of an osteoclast-selective, nonpeptide Src homology 2 inhibitor with in vivo antiresorptive activity. Proc. Natl. Acad. Sci. USA 97:9373-9378.

93.Shakespeare, W.C., R.S. Bohacek, M.D. Azimiora, K.J. Macek, et al. 2000. Structure-based design of novel bicyclic inhibitors for the Src SH2 domain. J. Med. Chem. 43:3815-3819.

94.Bohacek, R.S., D.C. Dalgarno, M. Hatada, V.A. Jacobsen, et al. 2001. X-ray structure of citrate bound to Src SH2 leads to high-affinity, bone-targeted Src SH2 inhibitor. J. Med. Chem. 44:660-663.

95.Wang, Y., C.A. Metcalf III, W.C. Shakespeare, R. Sundaramoorthi, T.P. Keenan, R.S. Bohacek, et al. Bone-targeted 2,6,9-trisubstituted purines: novel inhibitors of Src tyrosine kinase for the treatment of bone diseases. Bioorg. Med. Chem. Lett. (In press)

96.Sundaramoorthi, R., W.C. Shakespeare, T.P. Keenan, C.A. Metcalf III, Y. Wang, U. Mani, et al. Bone-targeted Src kinase inhibitors: novel pyrrolo- and pyrazolopyrimidine analogs. Bioorg. Med. Chem. Lett. (In press)

97.Vu, C., G.P. Luke, N. Kawahata, W.C. Shakespeare, Y. Wang, R. Sundaramoorthi, et al. Bone-targeted pyrido[2,3-d] pyrimidin-7-ones: potent inhibitors of Src tyrosine kinase as novel antiresorptive agents. Bioorg. Med. Chem. Lett. (In press).

98.Sawyer, T.K. 2002. Smart chemistry tackling complex biology. Targets: Innovations Genomics Proteomics 1:81-82.

\section{Address correspondence to:}

Tomi K. Sawyer

ARIAD Pharmaceuticals, Inc.

26 Landsdowne Street

Cambridge, MA 02139-4234, USA

e-mail: tomi.sawyer@ariad.com 